\title{
Vitamin-caused faulty perinatal hormonal imprinting and its consequences in adult age
}

\author{
G Csaba \\ Department of Genetics, Cell and Immunobiology, Semmelweis University, Budapest, Hungary
}

Received: March 18, 2017

Accepted: September 11, 2017

\begin{abstract}
Lipid-soluble vitamins (vitamins A, D, E, and K) are actually hormones (exohormones), as they can be directly bound by hormone receptors or are in connection with molecules, which influence hormone receptors. Vitamin D is a transition between endo- and exohormones and the possibility of similar situation in case of other lipid-soluble hormones is discussed. The perinatal exposition with these "vitamins" can cause faulty perinatal hormonal imprinting with similar consequences as the faulty imprinting by the synthetic endohormones, members of the same hormone family or industrial, communal, or medical endocrine disruptors. The faulty imprinting leads to late (lifelong) consequences with altered hormone binding by receptors, altered sexuality, brain function, immunity, bone development, and fractures, etc. In addition, as hormonal imprinting is an epigenetic process, the effect of a single exposure by fat-soluble vitamins is inherited to the progeny generations. As vitamins are handled differently from hormones; however, perinatal treatments take place frequently and sometimes it is forced, the negative late effect of faulty perinatal vitamin-caused hormonal imprinting must be considered.
\end{abstract}

Keywords: lipid-soluble vitamins, vitamin D, vitamin A, hormonal imprinting, faulty imprinting, perinatal exposures, epigenetic inheritance

\section{Introduction: The Physiological and Faulty Hormonal Imprinting}

Although the developing organism in the mother's womb is influenced first of all by the hormones of the mother, the fetus also synthesizes and secretes hormones, which are participating in the development and reactions of the organs (5). However, in this period, the hormone receptors are set to the quality and quantity of the mother's hormones (59), which can pass across the placenta $(48,63)$ and these hormones are needed for the development of the organs, which will be directed later by the extrauterine hormonal regulation $(61,76)$. Perinatally, in the late period of pregnancy and postnatally, in the first days of extrauterine life there is a critical period of development when already the own hormones of the infant are present, and the maternal ones do not disturb their effect. In that period, the real (extrauterine) receptor-hormone binding develops, which determines the reaction of the cell to the given hormone for a lifetime. The first encounter between the hormone and its receptor initiates the hormonal imprinting, which was observed at first more than 30 years ago by us (12) and is absolutely needed for the later normal receptor-hormone connection (13-15). In physiological cases, this is part of the postnatal development. However, in this critical period, the developing receptors can be misled by members of the hormone family or hormone-related foreign molecules as well as by the varying levels of

Corresponding address: Department of Genetics, Cell and Immunobiology, Semmelweis University

Nagyvárad tér 4, P.O. Box 370, Budapest 1445, Hungary

Phone: +36 303479 362; E-mail: csagyor@dgci.sote.hu 
the real hormones (16). In this case, faulty imprinting develops with lifelong consequences. These maybe alterations in the binding capacity of the receptors, which may result in an altered reaction of the cell to the hormone. This can be manifested also in the function of the cell and in the behavior of the cell or the whole organism. The faulty imprinting can influence the neurotransmitter level of the brain $(32,42,72)$, the sexual behavior of the male and female animals (22), the mineral content of the bones (50), the hormone content of immune cells $(17-19,31)$, etc. As faulty imprinting is an epigenetic phenomenon, its effect is inherited to the progenies of the imprinted cell in the same organism and to the progeny of the imprinted organism $(43,55,67)$.

Although most of the vitamins are coenzymes, certain vitamins $\mathrm{A}, \mathrm{D}, \mathrm{E}$, and $\mathrm{K}$ (lipid-soluble vitamins) are functioning as hormones binding to specific hormone receptors, or influencing the production of molecules, which bind to hormone receptors $(8,46,68,77)$. As some vitamins can be consumed by the developing infants, even their use is medically forced, the study of their faulty imprinting effects seems to be necessary.

\section{Facts}

\section{Effects measured by receptorial methods}

A single neonatal treatment with $25 \mu \mathrm{g}$ vitamin D3 significantly reduced the glucocorticoid receptor density of thymic cells in male rats, while there was no difference in females (27). However, in an other experiment (28), vitamin D3 did not compete in vitro with dexamethasone (DEX), a primary target of the receptor, while other synthetic steroid hormone (allylestrenol) did.

Vitamin A or retinoic acid exposition through breast milk was also observed (38). Treatments once a week for 3 weeks postnatally with $6 \mathrm{mg} /$ nursing mothers caused a significantly reduced density of thymic glucocorticoid recepors in adult age, whereas a similar treatment with $0.03 \mathrm{mg}$ all-trans-retinoic acid was found to be ineffective. Receptor affinity and binding by uterine estrogen receptors were unchanged.

Treating 3-week-old female rats with vitamin D3 and measuring the glucocorticoid binding of thymic cells, an elevated receptor density was shown (29). A single neonatal exposure to vitamin D3 appreciably influenced the steroid-like ouabain binding of myocardial ouabain receptors in adults (47).

In male adolescent and adult rats, the affinity of glucocorticoid receptors was influenced by neonatal single vitamin E treatment (24).

\section{Functional effects}

A neonatal single exposure to a small dosage $(2.5 \mu \mathrm{g})$ of vitamin D3 completely inhibited adult males' ejaculation, without influencing sexual desire (57). A high dose $(250 \mu \mathrm{g})$ neonatally abolished both sexual desire and ejaculation. Sexual activity was also depressed in both cases.

A single neonatal exposure of females to vitamin A (retinol) caused a significant decrease in the Meyerson index and a non-significant decrease in the lordosis quotient (23). Treatments at the first, third, and fifth days of life with all-trans-retinoic acid caused a nonsignificant decrease in the lordosis quotient of females and a significant increase in the time of the first ejaculation in males. 
A single neonatal treatment with vitamin E significantly reduced the Meyerson index and lordosis quotient in females. Among males, significantly more sexually inactive animals were present and no multiple ejaculations were observed in the treated group (30). Neonatal vitamin $\mathrm{K} 1$ exposure caused only slight changes in the same direction in both sexes (26).

Vitamin A (retinol) treatment was performed neonatally (at the first day) or retinoic acid treatments were performed in the first, third, and fifth days after birth. In adult (4 months old) rats, serum testosterone and progesterone levels were measured. Retinol significantly decreased both hormone levels, whereas retinoic acid reduced only the progesterone level (39). When the animals were treated in the 6th and 7th week after birth, retinol diminished testosterone level, without affecting progesterone level. Retinoic acid decreased testosterone level and elevated progesterone level.

A single perinatal vitamin A or retinoic acid exposure dramatically reduced the sexual activity of adult male rats (23), causing significant decrease in the Meyerson index.

The concentration of biogenic amines and their metabolites was studied after a single neonatal vitamin A or vitamin D treatment in five brain regions of 3-month-old rats. Vitamin A exposure significantly decreased hydroxy indole acetic acid level in each brain region (72). Vitamin D imprinting significantly elevated dopamine in the brainstem and homovanillic acid level in the striatum and hypothalamus. Transgenerational transmission of hormonal imprinting was also observed (73) in the brain of F1 generation of neonatally vitamin A- or D-imprinted dams. Vitamin A imprinting of dams always resulted in reduced tissue levels, whereas vitamin D imprinting resulted in increased biogenic amine levels.

Immune cells synthesize, store, and secrete hormones. After neonatal single vitamin A or vitamin D imprinting in 2-month-old male rats, T3 content was decreased in peritoneal lymphocytes as well as in monocytes and granulocytes of males, whereas the content of adrenocorticotropic hormone (ACTH) was decreased in female lymphocytes, monocytes, and granulocytes $(23,30,57)$. The endorphin content decreased in thymocytes of males. At the same time, vitamin D imprinting was ineffective. Transgenerational transmission of hormonal imprinting was observed $(23,30)$ in male offsprings: ACTH and T3 levels were almost doubled in the lymphocytes of vitamin A-imprinted mothers, whereas histamine content decreased to one third of control levels in vitamin D-treated mothers' progeny.

Single neonatal vitamin D3 imprinting significantly decreased the body weight of 3-month-old females and also significantly reduced bone mineral density (BMD) and bone mineral content (BMC) in males (50). A single neonatal DEX treatment decreased body weights of adults and increased BMD and BMC. Adult vitamin D treatment completely compensated for the changes caused by the neonatal DEX treatments (49).

Neonatal vitamin A imprinting significantly elevated apoptosis in peripheral blood lymphocytes (37). Vitamin A supplementation of rat dams during gestation and lactation decreased the antioxidant potential of the offsprings' liver with reduced dismutase/catalase activity ratio in the kidney (70). Embryonic development of vertebrates in general requires vitamin A for the fulfillment of developmental programs (60).

\section{Conclusions}

There are no human data in "Facts" section at all. This is understandable as perinatal faulty hormonal imprinting caused by hormones or endocrine disruptors $(35,62,75)$ was well known; however, vitamins were not suspected as pathogenic factors. Nevertheless, the data supplied by animal (mammalian) experiments clearly justify the danger of these interventions. 
Four vitamins are suspected of having hormone-like effects and each of them is lipidsoluble. These are vitamins A, D, E, and K. However, each lipid-soluble vitamin provoked clear faulty imprinting or imprinting-like effect. Both vitamins A and D have receptors in the nuclear steroid receptor superfamily. The receptors of vitamin $\mathrm{E}$ and $\mathrm{K}$ are less certainly defined; however, their connections with receptorial effects are not dubious. There are numerous animal experimental data and human observations on the effect of deficiency of these hormones in adults as well as on the effects of perinatal deficiency to adults. However, the systematic investigation of perinatal excess or perinatal single or continuous treatments were not performed $(1,66)$. This means that it seems difficult to unanimously declare that these treatments are so harmful, as the deficiency of these vitamins. However, the facts mentioned are enough for raising awareness that faulty hormonal imprinting is provoked by lipid-soluble vitamins and the observation of them is absolutely needed. Therefore, not only the well-known symptoms of hormone deficiency have to be observed, but the signs of disturbances caused by the related members of the hormone family, as the faulty imprinting disturbs the normal development of these receptors. As an example, the faulty imprinting by lipid-soluble vitamins cannot be exclusively manifested in organs or cells of their target organs (bone development or vision), but in the sexuality or thyroid function.

The inheritance of faulty hormonal imprinting is another important issue. This is not a genetic effect (a direct alteration of base sequences) but an epigenetic one, the trouble of gene manifestation by the change of the methylation patterns of the genes (34). In animalimprinting experiments, it is justified up to the third generation. In the progeny generations, the new imprinter effects are placed to the parentally imprinted ones altering the function of the genes further.

Vitamin A is a collective name for retinoids, such as retinol, retinal, and retinyl esters. The active form of these related molecules is retinoic acid, which can be bound by the retinoic acid receptor (RAR), which finds specific retinoic acid response elements in DNA (10), provoking the functions, which are characteristic to vitamin A (regulation of vision, cell growth, immunity, reproduction, etc.). However, it can also bind to the pregnane $\mathrm{X}$ receptor (PXR), which is responsible for the activation of enzymes of xenobiotic degradation $(53,54$, 58). In the perinatal period, excessive vitamin A can cross-react with the other members of steroid receptor superfamily (nuclear receptors), provoking faulty imprinting. Considering the presence of steroid receptors in different cells and organs and knowing that it can influence 530 genes (52), the pleiotropic effect of this faulty imprinting is understandable.

Vitamin A is not similar to the other target hormones of the steroid receptor superfamily, however, vitamin D is structurally a steroid hormone. Its receptor [vitamin D receptor (VDR)] is a typical steroid receptor, which in case of activation forms a heterodimer with RAR and the receptor complex finds the response elements in the DNA. VDRs are present in many kinds of cells and this explains why so many functions are influenced by its deficiency or excess. As earlier only its exclusive effect on calcium metabolism was believed, the research of the last decades emphasizes its pleiotropic effects from the immunity to the neural system and sugar metabolism $(41,45)$. It epigenetically regulates about 2,700 different genes $(40)$, in about 35 tissues, which carry VDRs (51).

Vitamin $\mathrm{E}$ is an antioxidant, which can be found in the normal diet. The name covers two substances: tocopherol and tocotrienol. These substances are recognized by the receptors of different hormone-like molecules, as estrogens and endocrine disruptors and can be bound by them $(11,56)$. By this mechanism, they participate in the mechanism of estrogen receptor 
beta (ER-beta) and PXR-induced gene expression. These receptors are members of the nuclear steroid receptor superfamily. Upon ligand binding, they form a heterodimer with the retinoid $\mathrm{X}$ receptor (74). Vitamin $\mathrm{E}$, which earlier was believed to be only an antioxidant, now is referred to as a hormone-like molecule.

The name vitamin K covers two substances, vitamin K1 (menadione) and vitamin K2 (menaquinones). After its discovery, it was believed to be a coenzyme for a carboxylase. However, new observations demonstrated its binding to steroid receptors as well as to the PXR. Consequently, it influences gene transcription $(2,3,44)$ in many organs and cells from bones (osteoblasts) to the endothelial cells.

Hormones are molecules synthesized and secreted by endocrine glands of an organism, participating in the chemical regulation. Vitamins are molecules which are not produced by the organism inside, but they are present in nourishment and after the assimilation they help different mechanisms which are absolutely needed for the normal function of an animal's life. These are the textbook descriptions. However, there is a vital vitamin, named vitamin D, which is produced inside the organism by the skin under the effect of sunshine and displays hormonal effects. From this aspect, the skin is an endocrine gland, the largest in the whole system, which not only synthesizes a rather effective hormone (vitamin D) but have receptors for many hormones of the system (78). This also means that there is a transition between the hormones (endohormones) and vitamins (exohormones). Considering the presently accepted nomenclature, each exohormone is lipid-soluble vitamin. They are named vitamins because in the time of their discovery the hormonal effects of them were unknown. However, they completely fulfill the requirements for hormone-being (20). Vitamin D was a real endohormone, for example in Africa, where the sun (the inducer of vitamin D synthesis) was shining continuously and from where the man originated. However, it was a vitamin in the time of its discovery in the foggy England, where vitamin D-rich cod liver oil was necessary for preventing rickets. Vitamin D would be the duck-mole of vitamin-hormone, a transition between the "vitamins" and hormones. However, it is also possible that other lipid-soluble vitamins were produced as hormones by some organs in the human organism "once upon a time" and later, because of an unknown reason, dismantled from the organism and became "vitamins." This may refer to vitamin A, which is also sensitive to sunlight; however, its content is reduced in the skin by it (6). Vitamin E is also present in the skin, which together with vitamin A has an antioxidant-scavenging potential, therefore protecting the skin from the deleterious effects of UV rays $(69,71)$. It is also possible that not only the lipid-soluble vitamins were able to do this dismantling, as vitamin $C$ is synthesized in most of the animal world, and only in case of a few species (e.g., in man and guinea pig) must be consumed from extra-organismic source.

The abovementioned facts and theories point to the present-day vitamine/hormone problems: the skin is not able to fulfill its endocrine function perinatally as the inducer, the sunlight is not present at delivery or after it, the hormone (e.g., vitamin D) allowance is deficient and this could cause or promote diseases or developmental abnormalities. Consequently, it must be supplemented. However, the exohormones (e.g., dietary or medicinal vitamin A or D) - at least in one part of their function - are acting as real hormones in the perinatal critical period of receptor development (when their dosage is also uncertain) and can execute faulty hormonal imprinting. As it was shown in the "facts" of the paper, this is the situation, indeed. This means that the doctors prescribe these substances as vitamins, which are needed for the health of the infant and these "vitamins" act as hormones for preparing conditions, which lead to the manifestation of diseases at adult age $(4,7,9,21,33,36)$. For 
this effect, the doctors, who prescibe recipes, or the parents who give these "vitamins" without prescription, are not the chief responsible persons, these are rather the advertisements in the media and mainly the name: vitamin. If these substances would be called "exohormones," the doctors would be more cautious and the lipid-soluble vitamins would be sold - in contrast to the present custom - in pharmacies and possibly for prescription. At present, the vitamins in general are not drugs (medicaments) but food supplements, so there is a possibility for mixing them into anything and can be bought anywhere and the people are crazing for these mixtures believing that the "vitamin" is always healthy.

In our modern age, the air, the water, and the food are full of endocrine disruptors (pesticides, plasticizers, soy phthalates, etc.). Medical authorities are fighting against the use of them with scarce success as they are used by the extremely growing industry directed by the demands of the growing population as well as by the hunt for money. At the same time, medical interventions are performed perinatally for preventing deficiency diseases (e.g., vitamin supplementation and fortification) as well as for assisting medical activity (e.g., oxytocin treatment for inducing delivery). It is not dubious that supplementation of vitamin D (or A) could be needed, however not only the positive effects should be emphasized, but the negative ones also must be considered. Without this, the perinatal lipid-soluble vitamin treatments can be listed among the disastrous effects of endocrine disruptors. In addition, faulty imprinting is not a time-dependent phenomenon: it is a developmental phase-dependent process, which can take place in any sensitive phases of our lives, or in developing cells (e.g., in the bone marrow) $(19,25,27)$. Considering also the epigenetically inherited character of perinatal hormonal imprinting, the future seems to be more hopeless $(64,65)$.

\section{REFERENCES}

1. Azars Braesco V, Pascal G: Vitamin A in pregnancy: requirements and safety limits. Am. J. Clin. Nutr. 71, 1325-1333 (2000)

2. Azuma K, Horie-Inoue K, Ouchi Y, Inoue S (2011): Chapter 11 - vitamin K as a ligand of steroid and xenobiotic receptor. In: Advances in Medicine and Biology (Vol. 21), ed Berhardt LV, Nova Science Publishers, Hauppauge, pp. 209-216

3. Azuma K, Inoue S: Vitamin K function mediated by activation of steroid and xenobiotic receptor. Clin. Calcium 19, 1770-1778 (2009)

4. Barker DJ: Sir Richard Doll lecture. Developmental origins of chronic disease. Public Health 126, 185-189 (2012)

5. Bernal J: Thyroid hormone receptors in brain development and function. Nat. Clin. Pract. Endocrinol. Metab. 3, 249-259 (2007)

6. Berne B, Nilsson M, Vahlquist A: UV irradiation and cutaneous vitamin A: an experimental study in rabbit and human skin. J. Invest. Dermatol. 83, 401-404 (1984)

7. Calkins K, Devaska SU: Fetal origins of adult disease. Curr. Probl. Pediatr. Adolesc. Health Care 41, $158-176$ (2011)

8. Carlberg C: Lipid soluble vitamins in gene regulation. Biofactors 10, 91-97 (1999)

9. Charles MA, Delpierre C, Bréant B: [Developmental origin of health and adult diseases (DOHaD): evolution of a concept over three decades]. Med. Sci. (Paris) 32, 15-20 (2016)

10. Chytil F: Vitamin A: not for vision only. Br. J. Nutr. 82, 161-162 (1999)

11. Comitato R, Nasaretnam K, Leoni G, Ambra R, Canali R, Bolli A, Marino M, Virgili F: A novel mechanism of natural vitamin E tocotrienol activity: involvement of ER-beta signal transduction. Endocrinol. Metab. 297, E427-E437 (2009)

12. Csaba G: Phylogeny and ontogeny of hormone receptors: the selection theory of receptor formation and hormonal imprinting. Biol. Rev. Camb. Philos. Soc. 55, 47-63 (1980) 
13. Csaba G: Phylogeny and ontogeny of chemical signaling: origin and development of hormone receptors. Int. Rev. Cytol. 155, 1-48 (1994)

14. Csaba G: Hormonal imprinting: its role during the evolution and development of hormones and receptors. Cell Biol. Int. 24, 407-414 (2000)

15. Csaba G: Hormonal imprinting: phylogeny, ontogeny, diseases and possible role in present-day human evolution. Cell Biochem. Funct. 26, 1-10 (2008)

16. Csaba G: The biological basis and clinical significance of hormonal imprinting, an epigenetic process. Clin. Epigenet. 2, 187-196 (2011)

17. Csaba G: The immuno-endocrine system: hormones, receptors and endocrine function of immune cells. The packed-transport theory. Adv. Neuroimmunol. Biol. 1, 71-85 (2011)

18. Csaba G: Hormones in the immune system and their possible role. A critical review. Acta Microbiol. Immunol. Hung. 61, 241-260 (2014)

19. Csaba G: Immunoendocrinology: faulty hormonal imprinting in the immune system. Acta Microbiol. Immunol. Hung. 61, 89-106 (2014)

20. Csaba G: Faulty perinatal hormonal imprinting caused by exogeneous vitamin D - dangers and problems. Austin J. Nutr. Food Sci. 4, 1075-1080 (2016)

21. Csaba G: The faulty perinatal hormonal imprinting as functional teratogen. Curr. Pediatr. Rev. 12, 222-229 (2016)

22. Csaba G: The present and future of human sexuality: impact of faulty perinatal hormonal imprinting. Sex. Med. Rev. 5, 163-169 (2017)

23. Csaba G, Gaál A: Effect of perinatal vitamin A or retinoic acid treatment (hormonal imprinting) on the sexual behavior of adult rats. Hum. Exp. Toxicol. 16, 193-197 (1997)

24. Csaba G, Inczefi-Gonda Á: Neonatal vitamin E treatment induces long term glucocorticoid receptor changes: an unusual hormonal imprinting effect. Life Sci. 63, 101-105 (1998)

25. Csaba G, Inczefi-Gonda Á: Direct and transgenerational effect of benzpyrene treatment at adolescent age on the uterine estrogen receptor and thymic glucocorticoid receptor of the adult rat. Acta Physiol. Hung. 86, 29-36 (1999)

26. Csaba G, Inczefi-Gonda Á: Effect of single neonatal vitamin K1 treatment (imprinting) on the binding capacity of thymic glucocorticoid and uterine estrogen receptors of adolescent and adult rats. Life Sci. 65, PL1-PL5 (1999)

27. Csaba G, Inczefi-Gonda Á: Effect of vitamin D(3) treatment in the neonatal or adolescent age (hormonal imprinting) on the thymic glucocorticoid receptor of the adult male rat. Horm. Res. 51, 280-283 (1999)

28. Csaba G, Inczefi-Gonda Á: Similarities and dissimilarities of newborn and adolescent rats in the binding capacity of thymic glucocorticoid receptors. Mech. Ageing Dev. 122, 327-334 (2001)

29. Csaba G, Inczefi-Gonda Á: Molecules acting on receptor level at weaning, durably influence liver glucocorticoid receptors. Acta Physiol. Hung. 92, 33-38 (2005)

30. Csaba G, Karabélyos C: Influence of a single treatment with vitamin E or K (hormonal imprinting) of neonatal rats on the sexual behavior of adults. Acta Physiol. Hung. 87, 25-30 (2000)

31. Csaba G, Kovács P, Pállinger É: Impact of neonatal imprinting with vitamin A or D on the hormone content of rat immune cells. Cell Biochem. Funct. 25, 717-721 (2007)

32. Csaba G, Tekes K: Is the brain hormonally imprintable? Brain Dev. 27, 465-471 (2005)

33. Dörner G: Environment- and gene-dependent human ontogenesis, sociogenesis and phylogenesis (eco-genoonto-socio-phylogenesis). Neuro Endocrinol. Lett. 25, 164-168 (2004)

34. Fetahu IS, Höbaus J, Kállay E: Vitamin D and the epigenome. Eur. J. Physiol. 5, 164 (2014)

35. Frye CS, Bo E, Calamandrei G, Calza L, Dessi-Fulgheri F, Fernandez M, Fusani L, Kah O, Kajta M, Le Page Y, Patisaul HB, Venerosi A, Wojtowicz AK, Panzica GC: Endocrine disrupters: a review of some sources, effects, and mechanisms of actions on behaviour and neuroendocrine systems. J. Neuroendocrinol. 24, 144-159 (2012)

36. Fudvoye J, Bourguignon JP, Parent AS: Endocrine-disrupting chemicals and human growth and maturation: a focus on early critical windows of exposure. Vitam. Horm. 94, 1-25 (2014)

37. Gaál A, Bocsi J, Falus A, Szende B, Csaba G: Increased apoptosis of adult rat lymphocytes after single neonatal vitamin A treatment (hormonal imprinting). A flow cytometric analysis. Life Sci. 61, PL339-PL342 (1997)

38. Gaál A, Csaba G: Effect of retinoid (vitamin A or retinoic acid) treatment (hormonal imprinting) through breastmilk on the glucocorticoid receptor and estrogen receptor binding capacity of the adult rat offspring. Hum. Exp. Toxicol. 17, 560-563 (1998)

39. Gaál A, Csaba G: Testosterone and progesterone level alterations in the adult rat after retinoid (retinol or retinoic acid) treatment (imprinting) in neonatal or adolescent age. Horm. Metab. Res. 30, 487-489 (1998) 
40. Genuis SJ: Maternal and pediatric health outcomes in relation to gestational vitamin D sufficiency. Obstet. Gynecol. Int. 2015, 501829 (2015)

41. Greves NJ, McGrath JJ: Vitamin D as a neurosteroid affecting the developing and adult brain. Annu. Rev. Nutr. 34, 117-141 (2014)

42. Hashemi F, Tekes K, Laufer R, Szegi P, Tóthfalusi L, Csaba G: Effect of a single neonatal oxytocin treatment (hormonal imprinting) on the biogenic amine level of the adult rat brain: could oxytocin-induced labor cause pervasive developmental diseases? Reprod. Sci. 20, 1255-1263 (2013)

43. Hocher B: More than genes: the advanced fetal programming hypothesis. J. Reprod. Immunol. 104-105, 8-11 (2014)

44. Horie-Inoue K, Inoue S: Steroid and xenobiotic receptor mediates a novel vitamin K2 signaling pathway in osteoblastic cells. J. Bone Miner. Metab. 26, 9-12 (2008)

45. Hypponen E, Laara E, Reunanen A, Jarvelin MR, Virtanen SM: Intake of vitamin D and risk of type 1 diabetes: a birth-cohort study. Lancet 358, 1500-1503 (2001)

46. Igarashi M, Yogiahi Y, Mihara M, Takada I: Vitamin K induces osteoblast differentiation through pregnane X receptor-mediated transcriptional control of the Msx2 gene. Mol. Cell. Biol. 27, 7947-7954 (2007)

47. Inczefi-Gonda Á, Csaba G, Dobozy O: Effect of a single neonatal treatment with steroid hormone or steroid-like molecules on myocardial ouabain binding in the adult rat. Gen. Physiol. Biophys. 6, 279-283 (1987)

48. James SR, Franklyn JA, Kilby MD: Placental transport of thyroid hormone. Best Pract. Res. Clin. Endocrinol. Metab. 21, 253-264 (2007)

49. Karabélyos C, Horváth C, Holló I, Csaba G: Effect of neonatal glucocorticoid treatment on bone mineralization of adult nontreated, dexamethasone-treated or vitamin D3-treated rats. Gen. Pharmacol. 31, 789-791 (1998)

50. Karabélyos C, Horváth C, Holló I, Csaba G: Effect of neonatal vitamin D3 treatment (hormonal imprinting) on the bone mineralization of adult non-treated and dexamethasone treated rats. Hum. Exp. Toxicol. 17, 424-429 (1998)

51. Kidd PM: Vitamins D and K as pleiotropic nutrients: clinical importance to the skeletal and cardiovascular systems and preliminary evidence for synergy. Altern. Med. Rev. 15, 199-204 (2010)

52. King MW (2014): Integrative Medical Biochemistry. McGraw-Hill, New York

53. Kliewer SA: The nuclear pregnane $X$ receptor regulates xenobiotic detoxification. J. Nutr. $133,2444 \mathrm{~S}-2447 \mathrm{~S}$ (2003)

54. Kliewer SA, Goodwin B, Willson TM: The nuclear pregnane X receptor: a key regulator of xenobiotic metabolism. Endocr. Rev. 23, 687-702 (2002)

55. Kőhidai L, Lajkó E, Pállinger É, Csaba G: Verification of epigenetic inheritance in a unicellular model system: multigenerational effects of hormonal imprinting. Cell Biol. Int. 36, 951-959 (2012)

56. Landes N, Pfluger P, Kluth D, Birringer M, Rühl R, Böl GF, Glatt H, Brigelius-Flohé R: Vitamin E activates gene expression via the pregnane $\mathrm{X}$ receptor. Biochem. Pharmacol. 15, 269-273 (2003)

57. Mirzahosseini S, Karabélyos C, Dobozy O, Csaba G: Changes in sexual behavior of adult male and female rats neonatally treated with vitamin D3. Hum. Exp. Toxicol. 15, 573-576 (1996)

58. Moon JY, Gwak HS: Role of the nuclear pregnane X receptor in drug metabolism and the clinical response. Recept. Clin. Invest. 2, e.996 (2015)

59. Morreale de Escobar G, Obregon MJ, Escobar del Rey E: Role of thyroid hormone during early brain development. Eur. J. Endocrinol. 151(Suppl. 3), U25-U37 (2004)

60. Morris-Kay GM, Ward SJ: Retinoids and mammalian development. Int. Rev. Cytol. 188, 73-131 (1999)

61. Nucera C, Muzzi P, Tiveron C, Farsetti A, La Regina F, Foglio B, Shih SC, Moretti F, Della Pietra R, Mancini F, Sacchi A, Trimarchi F, Vercelli A, Pontecorvi A: Maternal thyroid hormones are transcriptionally active during embryo-foetal development: results from a novel transgenic mouse model. J. Cell. Mol. Med. 14, 2417-2435 (2010)

62. Palanza P, Nagel SC, Parmigiani S, Vom Saal FS: Perinatal exposure to endocrine disruptors: sex, timing and behavioral endpoints. Curr. Opin. Behav. Sci. 7, 69-75 (2016)

63. Patel J, Landers K, Li H, Mortimer RH, Richard K: Delivery of maternal thyroid hormones to the fetus. Trends Endocrinol. Metab. 22, 164-170 (2011)

64. Pembrey M, Saffery R, Bygren LO: Human transgenerational responses to early-life experience: potential impact on development, health and biomedical research. J. Med. Gen. 51, 563-572 (2014)

65. Pembrey ME: Time to take epigenetic inheritance seriously. Eur. J. Hum. Gen. 10, 669-671 (2002)

66. Penniston KL, Tanumihardjo SA: The acute and chronic toxic effects of vitamin A. Am. J. Clin. Nutr. 83, 191-201 (2006) 
67. Reichetzeder C, Dwi Putra SE, Hocher B: Developmental origins of disease - crisis precipitates change. Cell. Physiol. Biochem. 39, 919-938 (2016)

68. Reichrath J, Lehman B, Carlberg C, Varani J, Zouboulis CC: Vitamins as hormones. Horm. Metab. Res. 39, 7184 (2007)

69. Saurat JH: Skin, sun, and vitamin A: from aging to cancer. J. Dermatol. 28, 595-598 (2001)

70. Schnorr CE, Morrone Mda S, Weber MH, Lorenz R, Behr GA, Moreira JC: The effects of vitamin A supplementation to rats during gestation and lactation upon redox parameters: increased oxidative stress and redox modulation in mothers and their offspring. Food Chem. Toxicol. 49, 2645-2654 (2011)

71. Sorg O, Tran C, Saurat JH: Cutaneous vitamins A and E in the context of ultraviolet- or chemically-induced oxidative stress. Skin Pharmacol. Appl. Skin Physiol. 14, 363-372 (2001)

72. Tekes K, Gyenge M, Folyovich A, Csaba G: Influence of neonatal vitamin A or vitamin D treatment on the concentration of biogenic amines and their metabolites in the adult rat brain. Horm. Metab. Res. 41, 277-280 (2009)

73. Tekes K, Gyenge M, Hantos M, Csaba G: Transgenerational hormonal imprinting caused by vitamin A and vitamin $\mathrm{D}$ treatment of newborn rats. Alterations in the biogenic amine contents of the adult brain. Brain Dev. 31 , 666-670 (2009)

74. Traber MG: Vitamin E, nuclear receptors and xenobiotic metabolism. Arch. Biochem. Biophys. 423, 6-11 (2004)

75. Walker DM, Gore AC: Epigenetic impacts of endocrine disruptors in the brain. Front. Neuroendocrinol. 44, 1-26 (2017)

76. Williams GR: Neurodevelopmental and neurophysiological actions of thyroid hormone. J. Neuroendocrinol. 20, 784-794 (2008)

77. Zhou C, Assem M, Tay JC, Watkins PB, Blumberg B, Schuetz EG, Thummel KE: Steroid and xenobiotic receptor and vitamin D receptor crosstalk mediates CYP24 expression and drug-induced osteomalacia. J. Clin. Invest. 116, 1703-1712 (2006)

78. Zouboulis CC: The human skin as a hormone target and an endocrine gland. Hormones (Athens Greece) 3, 9-26 (2004) 